\title{
Design and space qualification of laser for laser altimeter
}

P. Meng, W. Shi, S. Jiang, M. Qi, Y. Deng, et al.

P. B. Meng, W. Z. Shi, S. Jiang, M. Qi, Y. T. Deng, X. Li, "Design and space qualification of laser for laser altimeter," Proc. SPIE 11852, International Conference on Space Optics - ICSO 2020, 1185220 (11 June 2021); doi: $10.1117 / 12.2599441$ SPIE. Event: International Conference on Space Optics - ICSO 2021, 2021, Online 


\section{International Conference on Space Optics-ICSO 2020}

Virtual Conference

30 March-2 April 2021

Edited by Bruno Cugny, Zoran Sodnik, and Nikos Karafolas
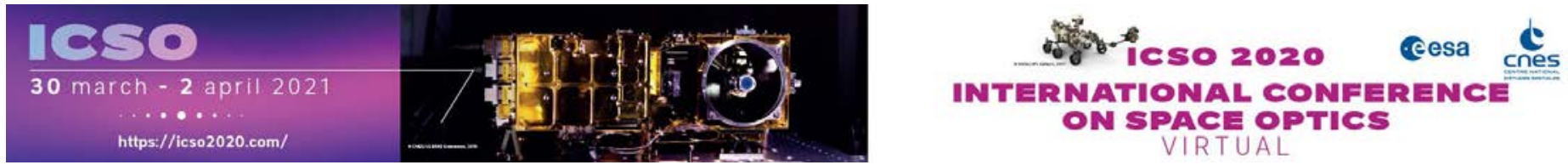

\section{Design and space qualification of laser for laser altimeter}

\section{Cesa isopmeatians ecnes}




\title{
Design and Space Qualification of Laser for Laser Altimeter
}

P.B. Meng, W.Z. Shi, S. Jiang, M. Qi, Y.T. Deng, X. Li

Beijing Institute of Space Mechanics \& Electricity, Key Laboratory for Space Laser Information

Perception Technology of CAST, Beijing, China, 100094

\begin{abstract}
A side-pumped actively Q-switched Nd:YAG laser with pulse energy of $>170 \mathrm{~mJ}$, pulse duration of $6 \sim 7 \mathrm{~ns}$ and $\mathrm{M}^{2} \approx 2.5$ has been miniaturized, light-weighted and dimensioned for high electrical to optical efficiency. The key performance parameters and space qualification of the laser will be presented. Its performance and space environment reliability is suitable for space-borne altimeter.
\end{abstract}

Keywords: Laser, altimeter, diode pumped, solid state laser, space qualification

\section{INTRODUCTION}

The high precision land elevation information provided by laser altimeter is very important to achieve large-scale and high-precision mapping product. Laser range finding is a well-established technology applied in a number of ground based instruments. The total number of space-borne altimeter instruments which are based on the same concept is still rather small ${ }^{1-6}$. Neither the ranging amplitude nor the environmental conditions prevent transfer of successful ground based laser ranging concepts to space. However, laser altimeter has become optimized electro optical systems and detailed engineering is required to transform their design without loss of functionality to meet conditions as minimum weight, maximum efficiency, minimum EMI and hence to qualify as laser altimeter for space flight. This difficulty also applies for laser subassembly of the altimeter system.

The laser design and space qualification for laser altimeter developed in progress are being presented and discussed in this paper.

\section{LASER REQUIREMENT}

Based on $500 \mathrm{~km}$ elevation measuring requirement and altimeter system design, a good performance laser with stringent requirements regarding mass and power consumption is required. The requirements of this laser are listed in Table 1.

Table 1. Performance requirements of the altimeter laser

\begin{tabular}{|c|c|c|}
\hline Parameter & Requirement & Result \\
\hline Laser wavelength (in vacuum) & $1064.0 \mathrm{~nm} \pm 0.5 \mathrm{~nm}$ & $1064.4 \mathrm{~nm}$ \\
\hline Laser pulse energy at begin of lifetime & $>170 \mathrm{~mJ}$ & $172.1 \mathrm{~mJ}$ \\
\hline Pulse repetition rate & $1 \mathrm{~Hz} \sim 5 \mathrm{~Hz}$ & $1 \mathrm{~Hz} \sim 5 \mathrm{~Hz}$ \\
\hline Pulse width (FWHM) & $4 \mathrm{~ns} \sim 8 \mathrm{~ns}$ & $6.8 \mathrm{~ns}$ \\
\hline Beam quality factor $M^{2}$ & $<3$ & 2.5 \\
\hline Beam Divergence & $\leq 800 \mu \mathrm{rad}$ & $700 \mu \mathrm{rad}$ \\
\hline Pointing stability $(2 \sigma, 8 \mathrm{~min})$ & $\leq 80 \mu \mathrm{rad}$ & $41.5 \mu \mathrm{rad}$ \\
\hline Weight & $\leq 8 \mathrm{~kg}$ & $\begin{array}{l}\text { Laser head: } 4.9 \mathrm{~kg} \\
\text { Laser electronics box: } 1.8 \mathrm{~kg}\end{array}$ \\
\hline Power consumption & $\leq 20 \mathrm{~W} @ 42 \mathrm{~V}, 3 \mathrm{~Hz}$ & 17 W@42 V, 3 Hz \\
\hline Lifetime & $\geq 1 \times 10^{8}$ & Undergoing \\
\hline
\end{tabular}




\section{LASER DESIGN}

\subsection{Laser optical summary}

The High Output Maximum Efficiency Resonator (HOMER) class design of diode-pumped solid state oscillator-only can produce beam quality and pulse energy typically associated with master oscillator power amplifier (MOPA) system. The HOMER lasers achieve this with high efficiency, low part count, and estimated long life. Based on requirement of lifetime ( $\sim 10^{8}$ shots) and experience learned by other space-borne lasers, a quasi-continuous-wave diode-side-pumped, electro-optic Q-switched Nd:YAG laser is selected. A schematic of the laser resonator is shown in Figure 1.

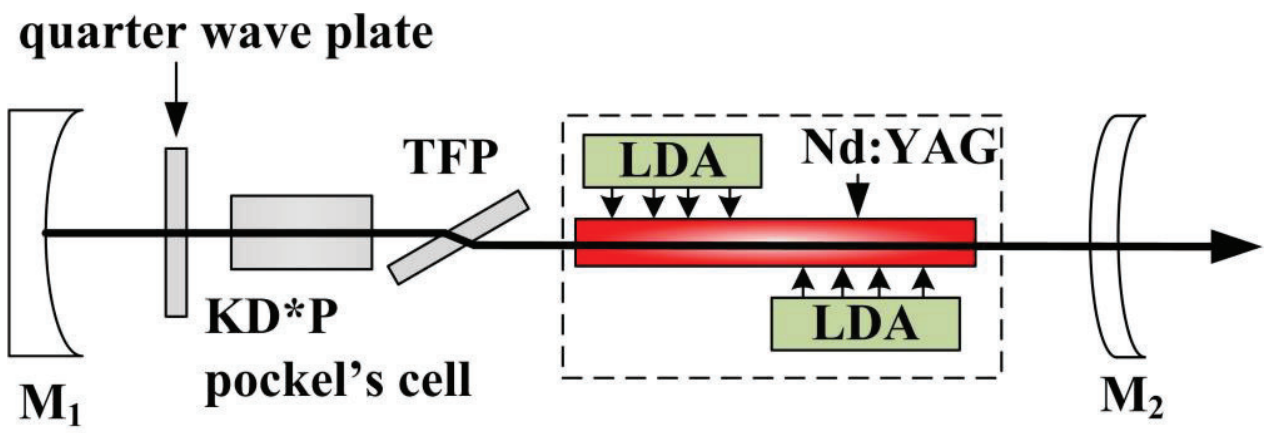

Figure 1. Schematic diagram of the laser resonator.

In order to obtain uniform gain distribution, the laser rod is mounted in a pump cavity with three laser diode pump array (LDA) groups. The mutual angle of the three groups is $120^{\circ}$. The pump lights are reshaped with three structures. For increasing the pump efficiency, the structures' surfaces are coated with golden coatings. The emitting wavelength of LDA is selected at $(808.5 \pm 0.5) \mathrm{nm} @ 20^{\circ} \mathrm{C}$ to obtain high absorption efficiency. A number of cavity design optimizations have been evaluated and tested systematically on breadboard level in order to achieve maximum coupling of optical pump power into the laser gain medium. The gain distribution is shown in Figure 2. To produce a gain-switched laser pulse of $1064 \mathrm{~nm}$, an active Q-switch comprised of KD*P pockel's cell, a quarter wave plate and a thin film polarizer (TFP), is employed. In order to achieve the large TEM $0_{00}$ mode volume, a Graded Reflectivity Mirror (GRM)-based concave-convex unstable resonator is chosen. After optimization, the final optical design uses a $27 \mathrm{~cm}$ resonator length. Based on this design, the required laser parameters could be generated using the available LDA pump power. The laser performance is shown in Table 1. The pulse envelope and far field distribution are shown in Figure 3.

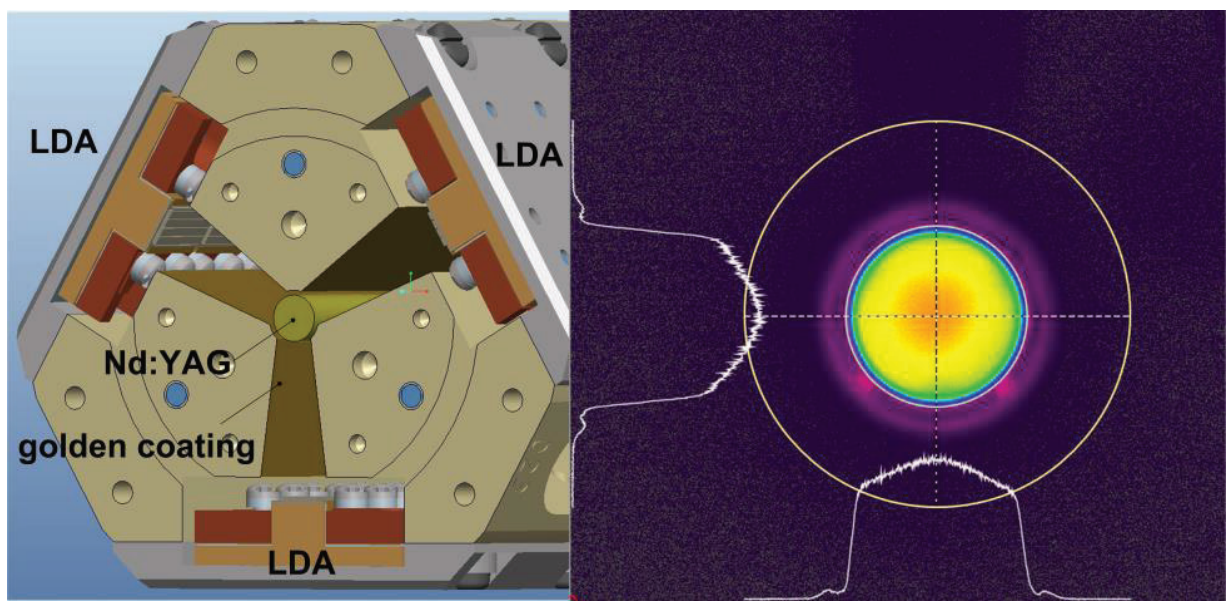

Figure 2. Pump module (left) and gain distribution (right). 


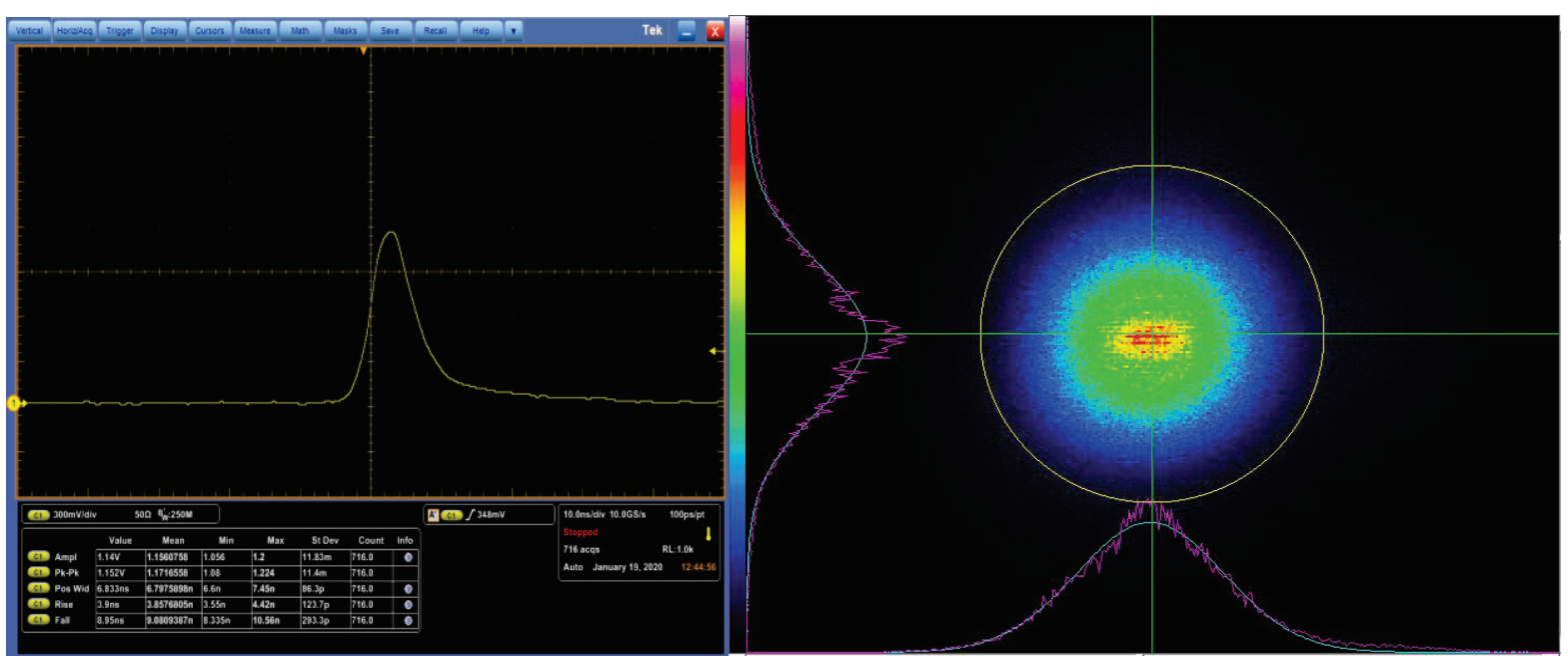

Figure 3. Pulse envelope (left) and far field distribution (right).

All delivered optics that have coatings will use witness samples to go through laser induced damaged testing (LIDT). Using the LIDT values along with models and verified experimental results over the past decade allows the laser team to know that energy level is safe for the laser to run at a specific configuration.

\subsection{Electrical summary}

The laser electronic box serves as the electrical interface between the laser and the instrument power and data systems. The laser electronic box is composed of four major subassemblies, each with a dedicated printed circuit card. These include the internal converter, the boost converter, the control electronics, and the Q-switch driver electronics. The primary function of the laser electronic box is delivering clean, tightly regulated, $\sim 200 \mu$ s wide, $\sim 100$ A current pulses to the laser diodes and $3200 \mathrm{~V}$ voltage pulses to the KD*P Pockel's cell. In addition, the unit also performs a number of other critical functions associated with laser operation.

The internal converter interfaces directly with the instrument $+42 \mathrm{~V}$ prime power. The control parameters include the time schedule, the charge voltage and current, LD driver pulse current amplitude and width, Q-switch driver voltage amplitude. The comprehensive controlling parameter can improve using convenience and provide the available driver in the late laser lifetime. The final power is $17 \mathrm{~W} @ 42 \mathrm{~V}, 3 \mathrm{~Hz}$ input, corresponding to plug-wall efficiency of 3\%.

\subsection{Mechanical summary}

The laser mechanical design includes a laser head and an electronic box. The laser head contains optics part and Qswitch driver circuit. The Q-switch driver circuit is set outside the optical part and Q-switch signal is fed through the floor to electro-optic Pockel's cell as shown in Figure 4. 

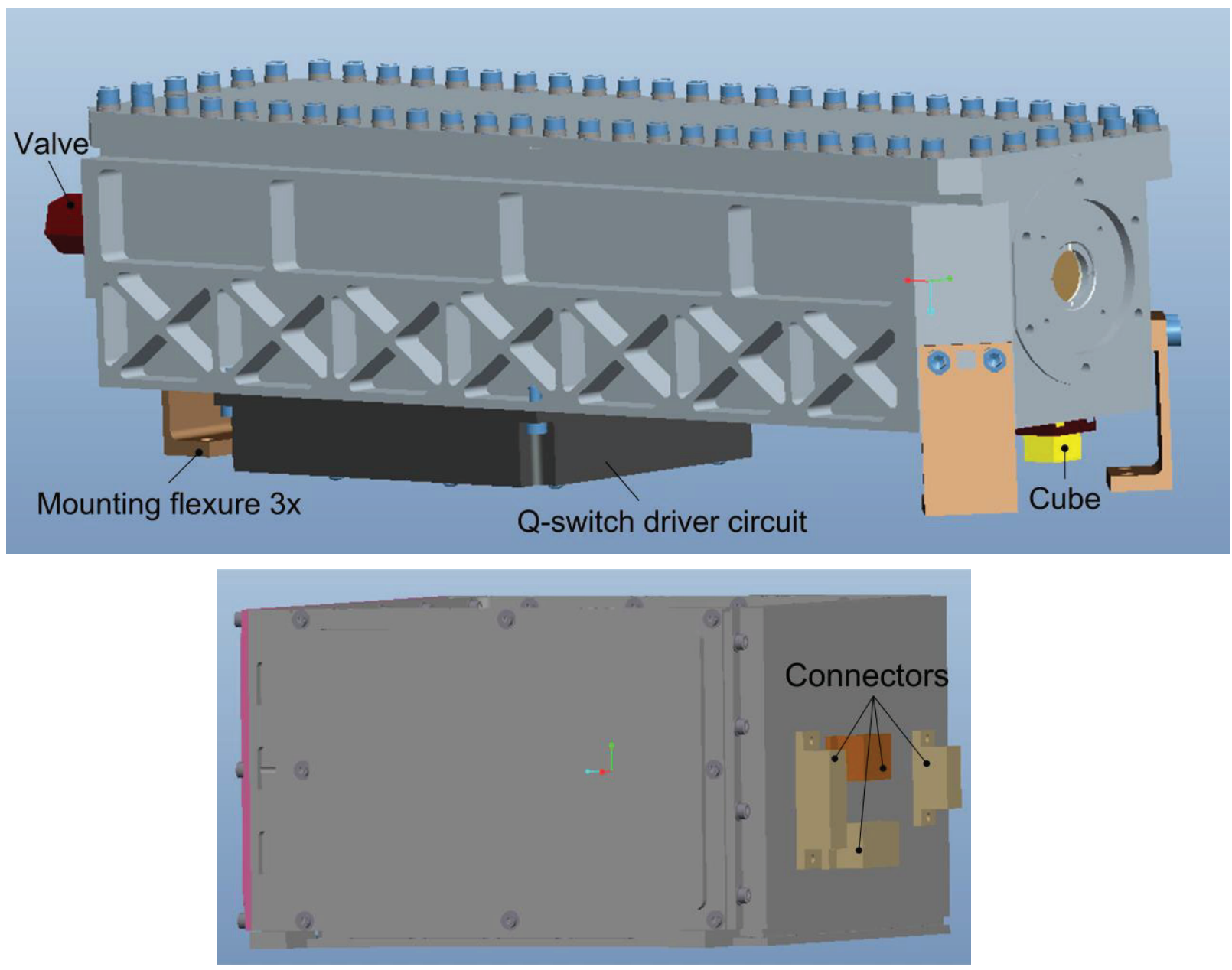

Figure 4.The full laser head (above); laser electronic box (below).

There are two considerations about the all metal sealed laser head design: to avoid contamination during altimeter and satellite integration and testing; to meet vacuum and ambient compatibility requirements. Based on the tilt and displacement misalignment sensitivity, the structure is designed to ensure vacuum compatibility and opto-mechanical stability. All materials and structure design are carefully considered to ensure radiation tolerance. The material of laser head cell is titanium. The laser head weighs $<5 \mathrm{~kg}$.

Four cards of the laser electronic box, the energy storage capacitor bank, and associated internal harnessing are tightly packaged within the electronics cavity. Signals are fed though four connectors. The electronic box weighs $<2 \mathrm{~kg}$.

\subsection{Thermal considerations}

The laser design requires cooling in order to maintain the desired Nd:YAG absorption pump wavelength from LDAs. Additionally, stable operating temperature must be maintained in order to guarantee the required turn-on time while in orbit. To minimize design and increase reliability, pump module is conductively cooled with the whole titanium cell and active temperature controller is not utilized inside. The thermal controlling system just needs to control the cell temperature. The optical bench and enclosure are designed such that internal thermal stresses will not affect laser performance. The laser system will be tested over a full survival range of $15^{\circ} \mathrm{C}$ to $25^{\circ} \mathrm{C}$ during thermal vacuum testing.

\section{QUALIFICATION TEST}

To guarantee the laser lifetime, pump laser diodes and optical elements were screened and derated. To meet requirement of internal cleanliness, materials and components used in laser head were carefully chosen, processed, and verified to be clean before integration. The complete laser head was vacuum baked at high temperature. After assembly and alignment, 
the laser proceeded through a series of test to validate design and characterize performance, including vibration test, thermal cycling test, thermal vacuum test and EMI/EMC test.

Laser robustness was confirmed through survival of $8.1 \mathrm{~g}$-rms vibration tests along each axis. In addition, the laser was exposed to thermal cycling tests in ambient and vacuum conditions for 12.5 and 3.5 cycles, respectively. Before and after the vibration test, thermal cycling test and thermal vacuum test, the laser performance was measured. There were almost no differences as shown in Table 2. During thermal vacuum cycles, the laser electro-optical performance including energy, pulse width and divergence was characterized. Little difference between the performance in ambient and vacuum conditions validated the structure stability and excellent sealed performance (leak rate $10^{-7} \mathrm{~Pa} \cdot \mathrm{m}^{3} / \mathrm{s}$ level). The laser performance during the 3.5 thermal vacuum cycles in vacuum was shown in Figure 5. Due to appropriate diode spectrum, doped concentration, low sensitive resonator, and stable structure, the variety of energy and divergence was $\pm 2 \%$ (P-V) in the range of $18{ }^{\circ} \mathrm{C} \sim 22^{\circ} \mathrm{C}$, and the variety of pulse width was $\pm 0.5 \mathrm{~ns}$. When the temperature reached to $15^{\circ} \mathrm{C}$, energy increased to about $180 \mathrm{~mJ}$, but divergence increased to $0.9 \mathrm{mrad}$. When the temperature reached to $25{ }^{\circ} \mathrm{C}$, energy decreased to about $160 \mathrm{~mJ}$, and divergence also increased to $0.92 \mathrm{mrad}$. However, the laser can survive and keep healthy. EMI/EMC test was also successfully performed.

Table 2. Major performance test results recorded before and after the qualification test.

\begin{tabular}{|l|l|l|l|}
\hline \multicolumn{1}{|c|}{ Test conditions } & \multicolumn{1}{|c|}{ Energy } & Pusle width & Divergence \\
\hline Before vibration test & $170.1 \mathrm{~mJ}$ & $6.8 \mathrm{~ns}$ & $0.7 \mathrm{mrad}$ \\
\hline After vibration test /before thermal cycling test & $171.1 \mathrm{~mJ}$ & $6.8 \mathrm{~ns}$ & $0.71 \mathrm{mrad}$ \\
\hline After thermal cycling test /before thermal vacuum test & $170 \mathrm{~mJ}$ & $7.3 \mathrm{~ns}$ & $0.71 \mathrm{mrad}$ \\
\hline After thermal vacuum test & $172.1 \mathrm{~mJ}$ & $6.8 \mathrm{~ns}$ & $0.7 \mathrm{mrad}$ \\
\hline
\end{tabular}
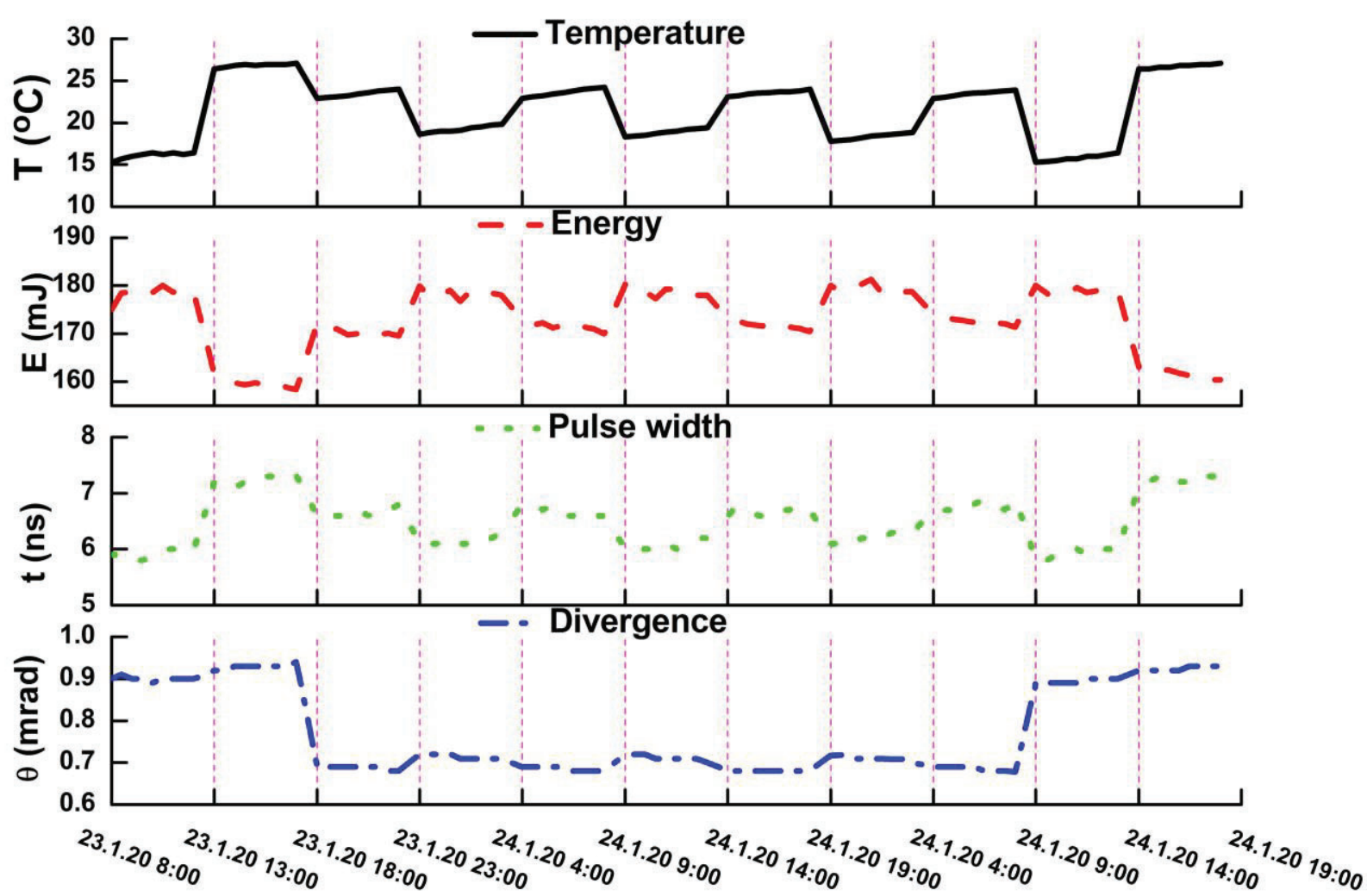

Figure 5. Laser performance during 3.5 thermal cycles in vacuum. 


\section{SUMMARY}

An engineering qualification model employing a robust HOMER class laser, met key performance parameters including pulse energy of $>170 \mathrm{~mJ}$, pulse width of $4 \mathrm{~ns} \sim 8 \mathrm{~ns}$, and beam quality factor $M^{2}$ of $<3$. The laser has large overhead in LDA derating, well known and measureable damage threshold, and quantified margins in thermal and optical space. Space qualification has been verified at this engineering qualification model. This system is an appropriate candidate for the laser altimeter.

\section{REFERENCES}

[1] Afzal R. S., "Performance of the GLAS laser transmitter," Proc. of SPIE, 6100: 610020 (2006).

[2] Anthony W. Y., George B. S., Anne M. N., et al, "In Space Performance of the Lunar Orbiter Laser Altimeter (LOLA) Laser Transmitter," Proc. of SPIE, 8182, 818208 (2011).

[3] Stysley P. R., Chiragh F., Frese E., et al, "Qualification of the solid state laser systems for the GEDI altimeter mission," Proc. SPIE 10636, 106360U (2018).

[4] Steinbrügge G., Stark A., Hussmann H., et al, "The performance of the BepiColombo Laser Altimeter (BELA) prior launch and prospects for Mercury orbit operations," Planetary and Space Science, 159:84-92 (2018).

[5] Sawruk N. W., Burns P. M., Edwards R. E., et al, "ICESat-2 laser Nd:YVO4 amplifier," Proc. SPIE, 10513 (2018).

[6] LI D., WANG M., "A review of high resolution optical satellite surveying and mapping technology," Spacecraft Recovery \& Remote Sensing, 41(2): 1-11(2020). 